\title{
Progress Report on the Tritium Reemission Simulation
}

\author{
J.F. Barbieri
}

May 1997

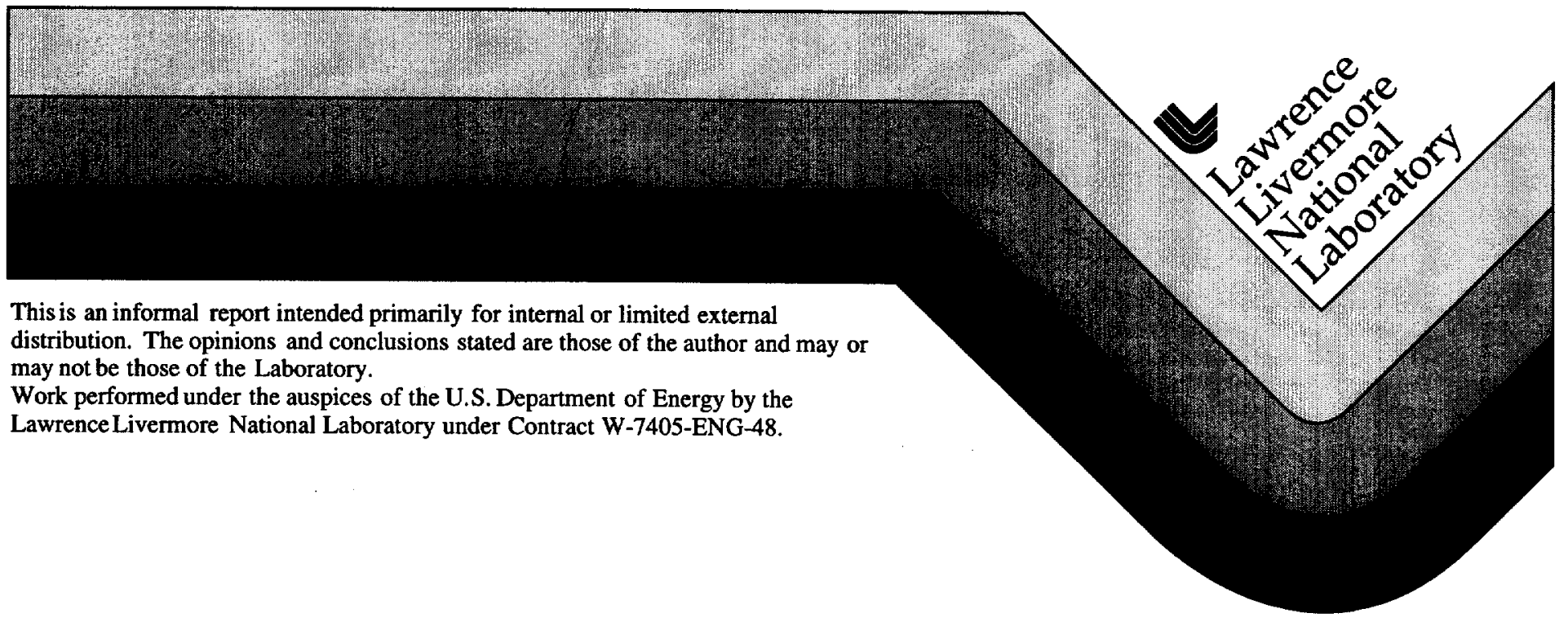




\section{DISCLAIMER}

This document was prepared as an account of work sponsored by an agency of the United States Government. Neither the United States Government nor the University of California nor any of their employees, makes any warranty, express or implied, or assumes any legal liability or responsibility for the accuracy, completeness, or usefulness of any information, apparatus, product, or process disclosed, or represents that its use would not infringe privately owned rights. Reference herein to any specific commercial product, process, or service by trade name, trademark, manufacturer, or otherwise, does not necessarily constitute or imply its endorsement, recommendation, or favoring by the United States Government or the University of California. The views and opinions of authors expressed herein do not necessarily state or reflect those of the United States Government or the University of California, and shall not be used for advertising or product endorsement purposes.

This report has been reproduced directly from the best available copy.

Available to DOE and DOE contractors from the Office of Scientific and Technical Information

P.O. Box 62, Oak Ridge, TN 37831

Prices available from (615) 576-8401, FTS 626-8401

Available to the public from the

National Technical Information Service

U.S. Department of Commerce

5285 Port Royal Rd.,

Springfield, VA 22161 


\title{
Progress Report on the \\ Tritium Reemission Simulation
}

\author{
James F. Barbieri \\ Lawrence Livermore National Laboratory \\ P.O. Box 808 \\ Livermore, CA 94550 \\ \& \\ Naval Air Warfare Center \\ China Lake, CA 93555-6001
}

\begin{abstract}
A mathematical model has been developed which computes the concentration of tritiated water reemitted into the atmosphere by surface evaporation and plant transpiration using the Penman-Monteith equation. Using these rates, and assuming a deposition velocity for tritium, a coupled set of diffusion equations are then solved which yield the concentration of tritiated water as a function of time. The model is driven by a number of enviromental parameters.
\end{abstract}





\section{Introduction}

If tritium (HT) is inadvertantly released into the atmosphere, it is capable of being transported long distances from the emitting source, before being deposited onto the soil surface [1]. Once on the ground, it is easily absorbed and transported into various layers of the soil and converted into tritiated water (HTO) [2]. Tritiated water is then reemitted into the atmosphere by surface evaporation and plant transpiration. Tritium reemission can occur over a period of weeks to years, during which evapotranspiration rates change over time due to diurnal effects, variations in air temperature, soil temperature, wind speed, soil moisture, and humidity. In addition, evapotranspiration rates are dependent on both vegetation type and soil properties.

It is clear that a large amount of environmental information is needed to adequately model tritium reemission, and under optimum conditions, it would be prudent to use as many measured values as possible. In emergency response conditions, however, many, if not all, of the driving parameters may not be available. With this in mind, we have developed a simulation in which require a minimum number of input variables. The obvious concern, of course, is that the simulation may, or may not, duplicate the actual enviromental conditions. In the following sections we shall discuss the effects of solar, atmospheric boundary layer, and environmental conditions as they affect the reemission of HTO.

\section{Solar Calculation and Radiation Balance Equations}

The energy which heats the vegetative canopy and the soil surfaces and is responsible for both evaporation and plant transpiration is primarily produced by the sun. A secondary source of energy is long wave radiation from the atmosphere. In order to derive the equations which describe the properties of the boundary layer we must first specify the amount energy that is available from these two sources. The amount of radiation $R_{\text {abs }}$ absorbed by the soil surface is a function of the global short wave radiation $S_{t}$ onto a horizontal surface and the air temperature $\theta_{\mathrm{a}}$ at the surface [24]:

$$
R_{\mathrm{abs}}=\mathrm{a}_{\mathrm{s}} \mathrm{S}_{\mathrm{t}}+\varepsilon_{\mathrm{a}} \sigma \theta_{\mathrm{a}}^{4}
$$

where $\mathrm{a}_{\mathrm{s}}$ is the short wave absorptivity (1-albedo) and $\varepsilon_{\mathrm{a}}$ is the atmospheric emissivity. The short wave absorptivity depends on the nature of the surface and the water content of the soil. For crops, $a_{s}$ varies from 0.75 to 0.85 [3] while for bare soils $a_{s}$ is often around 0.7 and increases linearly with water content of the surface layer to 0.88 at field capacity[4].

For clear sky conditions the atmospheric emissivity is calculated from the vapor concentration of air [4] using,

$$
\varepsilon_{\mathrm{a}}=0.58 \mathrm{c}_{\mathrm{va}}^{1 / 7}
$$

where $c_{v a}$ is the vapor concentration of air in $\mathrm{gm} / \mathrm{cc}$. Normally, the atmospheric vapor concentration is an input variable, however in this model, we approximate the saturation vapor concentration as a function of the minimum temperature $\theta_{\min }[3,7]$ ie

$$
c_{V_{A}}=\frac{\exp \left(31.3716-\frac{6014.79}{\theta_{\min }+273}-7.92495 \times 10^{-3}\left(\theta_{\min }+273\right)\right)}{\theta_{\min }+273}
$$

For cloudy sky conditions, the atmospheric emissivity can be approximated by the relationship [3]:

$$
\varepsilon_{\mathrm{ac}}=\left(1-0.84 \mathrm{c}_{1}\right) \varepsilon_{\mathrm{a}}+0.84 \mathrm{c}_{1}
$$


where $c_{1}$ is the fractional cloud cover. Normally, it is possible to estimate the fractional cloud cover $c_{1}$, however, if an estimate is unavailable, there is a simple relationship between fractional cloud cover and the atmospheric transmission coefficient $T_{1}$, where $T_{1}$ is defined to be the ratio of the potential radiation $Q_{0}$ to the measured daily global solar radiation $[3,10]$. It is

$$
c_{1}=2.33-3.33 \mathrm{~T}_{\mathrm{t}}
$$

Again the measured daily global solar radiation is usually a measured input variable, however, it too can be estimated if the latitude, Julian date and the maximum and minimum temperature are known [5]. The potential radiation, in $\mathrm{MJ}$, is calculated from [24]:

$$
Q_{0}=117.5\left[(\pi / 180) \cdot h_{s} \sin \phi \sin \delta+\cos \phi \cos \delta \sin h_{s}\right] / \pi
$$

where $\phi$ is the latitude, $\delta$ is the solar declination, and $\cos h_{s}=-\tan \phi / \tan \delta$. The solar declination is calculated from the day of the year - the Julian date, J using,

$$
\delta=-23.4 \cos \left(\frac{2 \pi}{365.0} \mathrm{~J}+10.0\right)
$$

The hourly ground level irradiance $S_{t}$, is calculated by multiplying the atmospheric transmission coefficient by the radiation received on a horizontal surface outside the earh's atmosphere at any time of day, or

$$
S_{t}=1360 T_{t} \sin e
$$

where $S$, has the units of $W / m^{2}$ and $e$ is the solar elevation angle defined by

$$
\sin \mathrm{e}=\sin \phi \sin \delta+\cos \phi \cos \delta \cos \left[0.2618\left(t-t_{0}\right)\right]
$$

where $t$ is the hour of the day and $t_{0}$ is the time of solar noon. Note, the angles in equations (5),(8), and $h_{s}$ are assumed to be in radians.

The second component of the radiation balance equation at the surface is long-wave radiation emitted from the earth's surface. The long-wave radiation contribution is proportional to the fourth power of the surface temperature. Unfortunately the surface temperature is rarely known, it is more convenient to write the surface emittance as the sum of two terms. The first term is proportional to the difference between the surface and air temperature and can be combined with a convective heat term, while the second term is proportional to the fourth power of the air temperature which is known. The temperature of the air can be estimated if the maximum and minimum daily air temperature are known:

$$
\theta_{\mathrm{a}}=0.5\left[\theta_{\max }+\theta_{\min }+\left(\theta_{\max }-\theta_{\min }\right) \cos 0.2618(\mathrm{t}-15.0)\right]
$$

where we have assumed that the air temperature reaches a maximum at around three in the afternoon. We can estimate the surface temperature (using the first two terms of the binomial expansion) as:

$$
\theta_{\mathrm{s}}^{4}=\left(\theta_{\mathrm{a}}+\Delta \theta\right)^{4}=\theta_{\mathrm{a}}^{4}+4 \theta_{\mathrm{a}}^{3} \Delta \theta
$$

assuming $\Delta \theta \ll<$. Subtracting $\varepsilon \sigma\left(\theta_{\mathrm{s}}\right)^{4}$ from $R_{\text {abs }}$ gives an estimate of the energy absorbed at the surface of the soil. This is called the net isothermal radiation $R_{n i}$. The second term in the binomial expansion $4 \varepsilon \sigma \theta^{3}$, which measures the temperature difference between the soil surface and the air, is called the radiative conductance: 


$$
\mathbf{K}_{\mathrm{r}}=4 \varepsilon \sigma \theta^{3}
$$

The radiative conductance is added to the boundary layer conductance to form a combined conductance for heat transfer in the atmospheric boundary layer. This will be discussed in the next section

\section{Boundary Layer Conductances for Heat and Water Vapor}

Heat and water vapor are transported by eddies in the turbulent atmosphere above a vegetative stand. Though the boundary layer above the canopy is complex, it is possible derive an expression for the boundary layer conductances as some function of the wind speed above the vegetative layer. Turbulence, on the other hand, is determined by a number of parameters, including surface roughness, canopy height, and the thermal stratification of the of the boundary layer. Campbell [7], (see also $[3,10]$ ) has developed an empirical relationship for the boundary layer conductance $K_{h}$ :

$$
K_{h}=\frac{k C_{h} u^{*}}{\ln \left[\left(z-d-z_{h}\right) / z_{h}\right]+\Psi_{h}}
$$

where $C_{h}$ is the volumetric specific heat of air and has a value of about $1200 \mathrm{Jm}^{-3} \mathrm{~K}^{-1}$ at $20^{\circ} \mathrm{C}$ at sea level, $\mathrm{u}^{*}$ is the friction velocity, $\mathrm{k}$ is von Karman's constant which is assumed to be about $0.4, \mathrm{z}$ is the height at which the wind speed and temperature is measured and is assumed to be above the vegetative canopy, $d$ is the zero plane displacement for the surface, $z_{h}$ is a surface roughness parameter for heat and $\psi_{h}$ is a stability correction factor for heat. The friction velocity is defined to be

$$
u^{*}=\frac{k u}{\ln \left[\left(z-d+z_{m}\right) / z_{m}\right]+\Psi_{m}}
$$

where $\mathrm{z}_{\mathrm{m}}$ and $\psi_{\mathrm{m}}$ are the roughness parameter and stability correction for momentum, and $\mathrm{u}$ is the mean wind speed measured at height $\mathrm{z}$.

The zero plane displacement and the roughness parameters are complex functions of the height, density, and shape of the roughness elements, however for a typical vegetative canopy the following empirical relationships have been obtained [8]:

$$
\begin{aligned}
& \mathrm{d}=0.77 \mathrm{~h} \\
& \mathrm{z}_{\mathrm{m}}=0.13 \mathrm{~h} \\
& \mathrm{z}_{\mathrm{h}}=0.2 \mathrm{z}_{\mathrm{m}}
\end{aligned}
$$

where $h$ is the height of the roughness element and is taken to be the mean height of the vegetative canopy.

The parameters $\psi_{\mathrm{h}}$ and $\psi_{\mathrm{m}}$ corrects the boundary layer conductance for the effects of buoyancy in the atmosphere. It is possible to define a stability parameter $\zeta$, which is a measure of the relative importance of the thermal and mechanical turbulence in boundary layer transport and is a function of the air temperature. It can be calculated from $[7,8,10]$ :

$$
\zeta=-\frac{\mathrm{kzgH}}{\mathrm{C}_{\mathrm{h}} \theta \mathrm{u}^{*^{3}}}
$$

where $g$ is the gravitational constant, $H$ is the sensible heat flux of the boundary layer, and $\theta_{\text {air }}$ is the temperature of the air in degrees Kelvin. $\mathrm{H}$ is defined as 


$$
\mathrm{H}=\mathrm{K}_{\mathrm{h}}\left(\boldsymbol{\theta}_{\text {soil }}-\boldsymbol{\theta}_{\text {air }}\right)
$$

The stability correction factors can now be expressed as a function of $\zeta$. When the atmosphere is stable, the surface (soil) temperature is lower than the air temperature hence $\mathrm{H}$ is negative and $\zeta$ is positive [8] and

$$
\Psi_{\mathrm{m}}=\Psi_{\mathrm{h}}=4.7 \zeta
$$

while for unstable conditions the surface temperature is higher than the air temperature, hence $\mathrm{H}$ is positive, and $\zeta$ is negative, Bussinger [8] suggests the following relationship,

$$
\begin{aligned}
& \psi_{\mathrm{h}}=-2.0 \ln \left[\frac{1+(1-16 \zeta)^{1 / 2}}{2}\right] \\
& \psi_{\mathrm{m}}=0.6 \Psi_{\mathrm{h}}
\end{aligned}
$$

Since the boundary layer conductance is a function of the heat flux density, and the heat flux density requires some knowledge of the boundary layer conductance, it is necessary to use an iterative scheme to determine an acceptable value of $K_{h}$. For sensible heat flow calculations, where the net isothermal radiation is used, the radiative conductance is added to the boundary layer conductance. We assume that the conductance for water vapor is the same as that for sensible heat, so the method used to calculate $C_{h}$ can be used to compute the boundary layer conductance for water vapor as well.

As stated above, it is known that tritium reemission is dynamically linked to plant transpiration rates, however plant transpiration is a function of the net isothermal radiation, the radiative and boundary layer conductances, and a number of vegetative specific parameters, including stomatal resistances and conductances. In the next section, we use the Penman-Monteith equation to calculate plant transpiration rates.

\section{Evapotranspiration and The Penman-Monteith Equation}

Comprehensive studies of the dymanics of plant transpiration processes can be found in a number of excellent references $[9,10,11,12]$. For our purposes we shall simply describe some of the parameters used to estimate transpiration rates. It is possible to compute a transpiration rate, $E$, for a vegetative canopy as a ratio of the vapor concentrations to the resistances to diffusion in the canopy and the atmospheric boundary layer [9] :

$$
E=\frac{c_{v s}-c_{v a}}{r_{v c}+r_{v a}}
$$

where $c_{v s}$ is the vapor concentration of the evaporating surface, $c_{v a}$ is the vapor concentration in the air above the canopy, $r_{\mathrm{w}}$ is the resistance to vapor diffusion in the canopy and $r_{\mathrm{va}}$ is the resistance to diffusion in the atmospheric boundary layer. The canopy resistance $r_{v c}$ is an equivalent resistance for all of the leaves within the canopy, hence it is a function of stomatal resistance, leaf area index (LAI), and the number of leaves in the canopy. Clearly, such information is not available, particularly in an emergency response scenario, however assuming such information was available, then the canopy resistance can be calculated from

$$
\frac{1}{r_{v c}}=\frac{\sum F_{i}}{r_{v s i}}
$$


where $\Sigma F_{i}$ is the sum over $n$ groups of leaves having an LAI of $F_{i}$, and $r_{v s i}$ is the stomatal resistance. The boundary layer resistance is just $r_{v a}=C_{h} / K_{h}$.

Since humidity near stomatal cavities is always near unity, we assume that the concentration of vapor at the evaporating surface is at saturation. The surface concentration can therefore be calculated using the canopy temperature [9]

$$
c_{\mathrm{va}}^{\prime}=\frac{\exp \left(31.3716-\frac{6014.79}{\theta}-7.92495 \times 10^{-3} \theta\right)}{\theta}
$$

where $\theta$ is the canopy temperature in degrees kelvin, and $c^{\prime}{ }_{v a}$ has the units of $\mathrm{g} / \mathrm{m}^{3}$. The prime indicates the surface concentration is at saturation.

There is an obvious problem with the formulation of eqn (18). In order to predict the transpiration rate, the canopy temperature must be known, however the transpiration rate influences the canopy temperature. If the difference between the canopy temperature and air temperature are ignored, and the transpiration rate is calculated using only air temperature, we can rewrite (18) as [7]

$$
E=\frac{c_{v s}^{\prime}-c_{v a}^{\prime}}{r_{v}}+\frac{c_{v a}^{\prime}-c_{v a}}{r_{v}}
$$

where the second term on the right is just the isothermal evaporation rate. The vapor concentration difference can be approximated as:

$$
c_{v s}^{\prime}-c_{v a}^{\prime} \approx s\left(T_{s}-T_{a}\right)
$$

where $s$ is the slope of the saturation vapor concentration function at the air temperature $T_{2}$ and is given by:

$$
s=\frac{c_{v}^{\prime}\left(\frac{L M_{w}}{R \theta}-1\right)}{\theta}
$$

where $L$ is the latent heat of vaporization in $J / g, M_{w}$ is the molecular mass of water $(0.018 \mathrm{~kg} / \mathrm{mole})$ and $R$ is the gas constant $(8.3143 \mathrm{~J} / \mathrm{mole}-\mathrm{K})$.

If the vegetative canopy is tall and the plants within the canopy are transpiring rapidly, an isothermal approximation may be adequate. In most cases, however, it is necessary to account for the difference between the air and plant temperatures[7]. Penman[13] combined (21) with the energy budget equation to obtain the well-known Penman equation for predicting potential evapotranspiration rates. Monteith[14] modified the Penman equation, forming the Penman-Monteith equation. We use the PenmanMonteith equation to predict evapotranspiration rates in a vegetative canopy. The energy balance for a vegetative canopy can be written as [13]

$$
R_{n i}-G-L E-K_{h r}\left(T_{s}-T_{a}\right)=0
$$

where $R_{n j}$ is the isothermal net radiation, $G$ is the ground heat flux density, $K_{h r}$ is the sum of the boundary layer and radiative conductances. The Penman-Monteith equation is a combination of (21) and (24):

$$
E=\frac{s}{s+\gamma^{*}} \frac{R_{\mathrm{ni}}-\mathrm{G}}{L}+\frac{\gamma^{*}}{s+\gamma^{*}} \frac{c_{\mathrm{va}}^{\prime}-c_{\mathrm{va}}}{r_{\mathrm{vc}}+r_{\mathrm{va}}}
$$


where $\gamma^{*}$ is the apparent psychrometer constant and is just

$$
\gamma^{*}=\frac{\mathbf{r}_{\mathrm{v}} \mathrm{K}_{\mathrm{hr}}}{\mathrm{L}}
$$

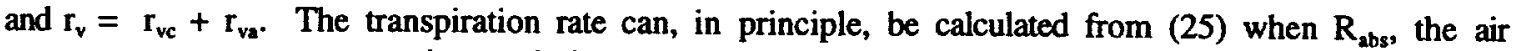
temperature, vapor concentrations and plant resistances are known. In practice, however, it is difficult to know the canopy resistances since it depends on the leaf water potential which is in turn a function of the transpiration rate. For our purposes, however, we use estimates from both the Biosphere-Atmosphere Transfer Scheme(BATS)[15] and the Simple Biosphere (SiB)[16] models to provide vegetative parameters necessary to compute evapotranspiration rates. These parameters are listed in appendix A.

\section{HT Transport and Conversion}

The principal mechanism for HT deposition within soil is gaseous diffusion into the free air space, ie. the air volume fraction within the soil. HT is depleted by oxidation due to organisms and enzymes distributed within the soil. Russell and Ogram [17], in the Ontario Tritium Dispersion Study developed a one dimensional simulation of HT transport and conversion to HTO within the soil layer and the subsequent HTO reemission into the atmosphere. We use their basic assumptions for modeling HT and HTO diffusing within the soil layer.

They assumed that HT gas diffuses rapidly to the free pore space within the soil layer and the subsequent microbial conversion of HT to HTO is controlled by a first order reaction coefficient, $\mathrm{K}$. Assuming the soil is rather shallow, and that the concentration of HT remain constant for a predetermined time period, it can be shown that a steady state HT concentration profile is rapidly established [18]. The transport equation for HT gas within the soil layer is

$$
\frac{d C_{T}}{d t}=D_{T} \frac{d^{2} C_{T}}{d z^{2}}-K C_{T}
$$

where $D_{T}$ is the effective $H T$ diffusion coefficient in soil, $C_{T}$ is the HT concentration in soil air, and $\mathrm{z}$ is the depth below the surface. If the soil surface is exposed to a constant concentration $X_{T}$ for a specific period of time $t_{0}$ then the surface boundary condition at the soil surface $z=0$ is just

$$
\mathrm{C}_{\mathrm{T}}=\mathrm{X}_{\mathrm{T}} \quad 0<\mathrm{t} \leq \mathrm{t}_{0}
$$

It is assumed that there is no HT diffusion below a certain depth $\mathrm{L}$, hence the boundary condition at $\mathrm{z}=\mathrm{L}$ is

$$
-D_{\mathrm{T}} \frac{\mathrm{dC}_{\mathrm{T}}}{\mathrm{d}}=0
$$

The solution to the HT transport equation, assuming small $\mathrm{L}$ is given by [18]

$$
\mathrm{C}_{\mathrm{T}}(\mathrm{z})=\frac{\mathrm{X}_{\mathrm{T}}}{\cosh (\alpha \mathrm{L})} \cosh [\alpha(\mathrm{L}-\mathrm{z})]
$$

where $\alpha=\left(K / D_{\mathrm{T}}\right)^{1 / 2}$. Note, $1 / \alpha$ is the scaling depth for $\mathrm{HT}$ penetration into the soil layer. Defining the flux $J$ to be the total amount of HT deposited on a given per unit area of soil for a specific period of time, and the deposition velocity $v_{d}$ to be the ratio of HT flux to the concentration of HT in the layer of atmosphere just above the soil, then 


$$
v_{d}=\frac{J}{X_{T}}
$$

Using Fick's law for diffusion, J becomes

$$
\begin{aligned}
J & =-\kappa_{\mathrm{a}} \mathrm{D}_{\mathrm{T}} \frac{d C_{\mathrm{T}}}{\mathrm{d}} \\
& =\kappa_{\mathrm{a}}\left(\mathrm{KD}_{\mathrm{T}}\right)^{1 / 2} \mathrm{X}_{\mathrm{T}} \tanh (\alpha \mathrm{L}) \\
& =\kappa_{\mathrm{a}}\left(\mathrm{KD}_{\mathrm{T}}\right)^{1 / 2} \mathrm{X}_{\mathrm{T}}
\end{aligned}
$$

for large $\alpha \mathrm{L}$

where $\kappa_{\mathrm{a}}$ is the fraction by volume of air in the soil. By combining (30) and (31) an expression for $\mathrm{K}$ in terms of the deposition velocity, diffusion coefficient, and the air volume fraction is obtained:

$$
\mathrm{K}=\frac{\mathrm{v}_{\mathrm{d}}^{2}}{\kappa_{\mathrm{a}}^{2} \mathrm{D}_{\mathrm{T}}}
$$

and the parameter $\alpha$ for the steady state solution for HT transport is

$$
\alpha=\sqrt{\mathrm{K} / \mathrm{D}_{\mathrm{T}}}=\frac{\mathrm{v}_{\mathrm{d}}}{\mathrm{\kappa}_{\mathrm{a}} \mathrm{D}_{\mathrm{T}}}
$$

A number of assumptions have been made which allow one to write a steady state solution. If any of these assumptions are not met, then (29) may not be valid and (26) must be solved by traditional numerical means. In addition to assumptions already made, (26) is a one dimensional transport equation, hence lateral subsurface flows are not adequately considered. In the next section we discuss HTO transport and reemission.

\section{HTO Transport and Reemission}

In addition to the assumptions described above, we also assume that any movement of water in the soil layer is primarily by diffusion, that is, advection is not important. This implies that there is limited rainfall and that transpiration takes place by either evaporation from the soil surface and by transpiration via root uptake by plants. The transport equation for HTO is

$$
\frac{d C_{O}}{d t}=D_{O} \frac{d^{2} C_{O}}{d z^{2}}-v_{O} \frac{d C_{O}}{d t}+\frac{\kappa_{a}}{\kappa_{w}} K C_{T}-K_{v} C_{O}
$$

where $C_{0}$ is the HTO concentration, $D_{0}$ is the effective HTO diffusion coefficient, $v_{0}$ is the ground water velociy, $\kappa_{w}$ is the fraction of water by volume in the soil, and $K_{v}$ is the rate constant for plant transpiration. $\mathrm{K}_{\mathrm{v}}$ can be written as [17]:

$$
\mathrm{K}_{\mathrm{v}}=\frac{\mathrm{E}}{\mathrm{K}_{\mathrm{w}} \mathrm{z}_{\mathrm{r}}}
$$

where $E$ is the plant transpiration rate and $z_{r}$ is the root zone thickness. Note, in this simulation we have assumed that the root density is constant for the entire root zone.

The surface boundary conditions are written as a function of the HTO flux at the soil surface: $z=$ 0 . (This is not strictly true, since HTO reemission in a vegetative canopy occurs throughout the entire canopy.) 


$$
-\kappa_{w} D_{O} \cdot \frac{d C_{o}}{d z}+\kappa_{w} v_{o} C_{o}=v_{e}\left[X_{O}-\gamma C_{o}\right]
$$

where $v_{c}$ is the HTO exchange velocity, $X_{0}$ is the concentration of HTO at the soil surface, and $\gamma$ is the humidity with units of $\left(\mathrm{m}^{3}\right.$ water $/ \mathrm{m}^{3}$ air). For the bottom of the soil layer $\mathrm{z}=\mathrm{L}$, we again assume no transport of HTO below this layer, hence the boundary condition at $\mathrm{L}$ is:

$$
-\kappa_{w} D_{O} \frac{d C_{O}}{d}+\kappa_{w} v_{O} C_{O}=0
$$

There is no known analytical solution of the HTO transport equation (34) together with the associated boundary conditions (36) and (37), instead we divide the soil layer into n layers, and solve the transport equation for each layer using finite difference techniques - see for instance, Strang[19]. Applying finite difference techniques to (34) leads to a system of $\mathbf{n}$ tridiagonal linear equations which can be solved using LU decomposition techniques [20]. The general form of the HTO transport equation for the $i^{\text {th }}$ layer with thickness $\Delta \mathrm{z}_{\mathrm{i}}$ and time step $\Delta \mathrm{t}$ is

$$
\begin{aligned}
& \mathrm{C}_{\mathrm{O}(\mathrm{i}-1)}\left[\frac{\Delta \mathrm{t}}{2 \Delta \mathrm{z}_{\mathrm{i}}}\left(\frac{-2 \mathrm{D}_{\mathrm{O}}}{\Delta \mathrm{z}_{\mathrm{i}}}-\mathrm{v}_{0}\right)\right] \\
& +\mathrm{C}_{\mathrm{O}(\mathrm{i})}\left[1+\frac{\Delta 2 \mathrm{D}_{\mathrm{O}} \Delta \mathrm{t}}{\Delta \mathrm{z}_{\mathrm{i}}^{2}}+\mathrm{K}_{\mathrm{v}} \Delta \mathrm{t}\right]+ \\
& +\mathrm{C}_{\mathrm{O}(\mathrm{i}+1)}\left[\frac{\Delta \mathrm{t}}{2 \Delta \mathrm{z}_{\mathrm{i}}}\left(\frac{-2 \mathrm{D}_{\mathrm{O}}}{\Delta \mathrm{z}_{\mathrm{i}}}+\mathrm{v}_{0}\right)\right]=\mathrm{C}_{\mathrm{O}(\mathrm{i})}^{\mathrm{P}}+\frac{\mathrm{K}_{\mathrm{a}}}{\kappa_{\mathrm{w}}} \mathrm{K} \Delta \mathrm{t} \cdot \mathrm{C}_{\mathrm{T}(\mathrm{i})}
\end{aligned}
$$

where $\mathrm{C}_{\mathrm{O}(\mathrm{i})}$ is the concentration of HTO in the $\mathrm{i}^{\text {th }}$ soil layer, $\mathrm{C}^{\mathrm{P}}{ }_{\mathrm{O}(i)}$ is the concentration of HTO from the previous time step and $C_{T(i)}$ is the concentraton of HT in the $i^{\text {th }}$ soil layer. Russell and Ogram [17] used an average $H T$ concentration in the entire soil layer replaceing the actual concentration for that layer. When we duplicated their assumption, unreasonable surface concentrations were obtained. The boundary conditions are imbedded in the $z_{i}=0$ and $z_{i}=L$ equations. In addition, $K_{v}=0$ for $z_{i}>z_{r}$, ie. plant transpiration effects do not occur in those layers outside the root zone layer.

For each time step $\Delta t$, the HT and HTO concentrations are calculated and the resuspended HTO flux is calculated at the soil surface. The flux is given by:

$$
\mathrm{F}_{\mathrm{HTO}}=\mathrm{v}_{\mathrm{e}} \mathrm{C}_{\mathrm{O}(1)}+\mathrm{EC}_{\mathrm{r}}
$$

where $C_{\alpha()}$ is the concentration of HTO in the surface layer, $C_{r}$ is the concentration of HTO in each soil layer within the root zone, $v_{e}$ is the surface evaporation rate, and $E$ is the plant transpiration rate.

\section{The Tritium Resuspension Simulation}

From an emergency response perspective, all of the environmental parameters described in appendix $\mathrm{A}$ are assumed constant for the entire simulation. In order to limit the number of dynamic parameters, the maximum time period (span) for the simulation is limited to a two week period, and the time step (resolution) is assumed to be one hour. We are currently assuming a single vegetative type, and a single soil type. Radiation input parameters consist of a starting Julian date and a latitude. Boundary layer input parameters are wind speed, the height at which the wind speed measurement was taken, canopy height, soil temperature, relative humidity, and maximum and minimum air temperature. 
The simulation is divided into two parts. The first part (preHTO) calculates evapotranspiration rates as a function of time, The second part (HTO) calculates the actual HTO concentration as a function of time. The input parameters for the second section is essentially a table of hourly HT concentrations at the soil surface. Both the surface evaporation rates and the plant transpiration rates are stored in a separate evapotranspiration input file. In addition, there are a number of parameters used by Russell and Ogram that are stored in a fixed parameter file. These include the important HT and HTO diffusion coefficients and the first order reaction coefficient. In figure 1., the general process used for determining the relevant evapotranspiration rates are shown

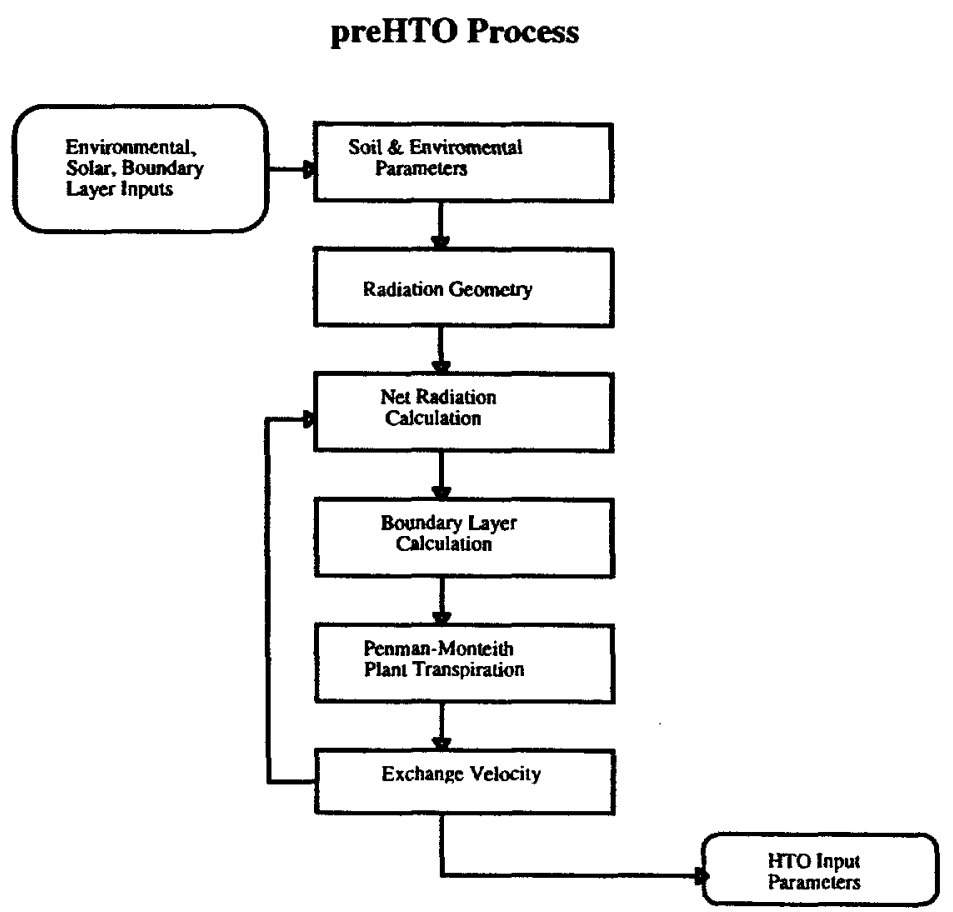

figure 1.

It should be noted that the iteration loop extends over only the most dynamic variables in the system. We have assumed thoughout the simulation, hourly time steps, and that solar radiation is the primary driver of the evapotranspiration rates. One very serious weakness in the current version of this simulation is the assumption of constant wind speed values. Our simulation shows that wind is a major contributor to changes in evapotranspiration rates.

The actual HTO calculation has a similar process diagram, figure 2., however in this case the calculation continues with the same HT concentration until it's value is changed by the user input or concentrations supplied by the ADPIC model. In the current implementation each new value of atmospheric HT has associated with it a time. When the simulation reaches that time, the concentration is automatically updated. In order to integrate this program into the suite of programs available to ARAC [21], a user defined interface program would be required. In addition, this program is intimately tied to environmental data, hence a vegetative data base is also required. 


\section{HTO Process}

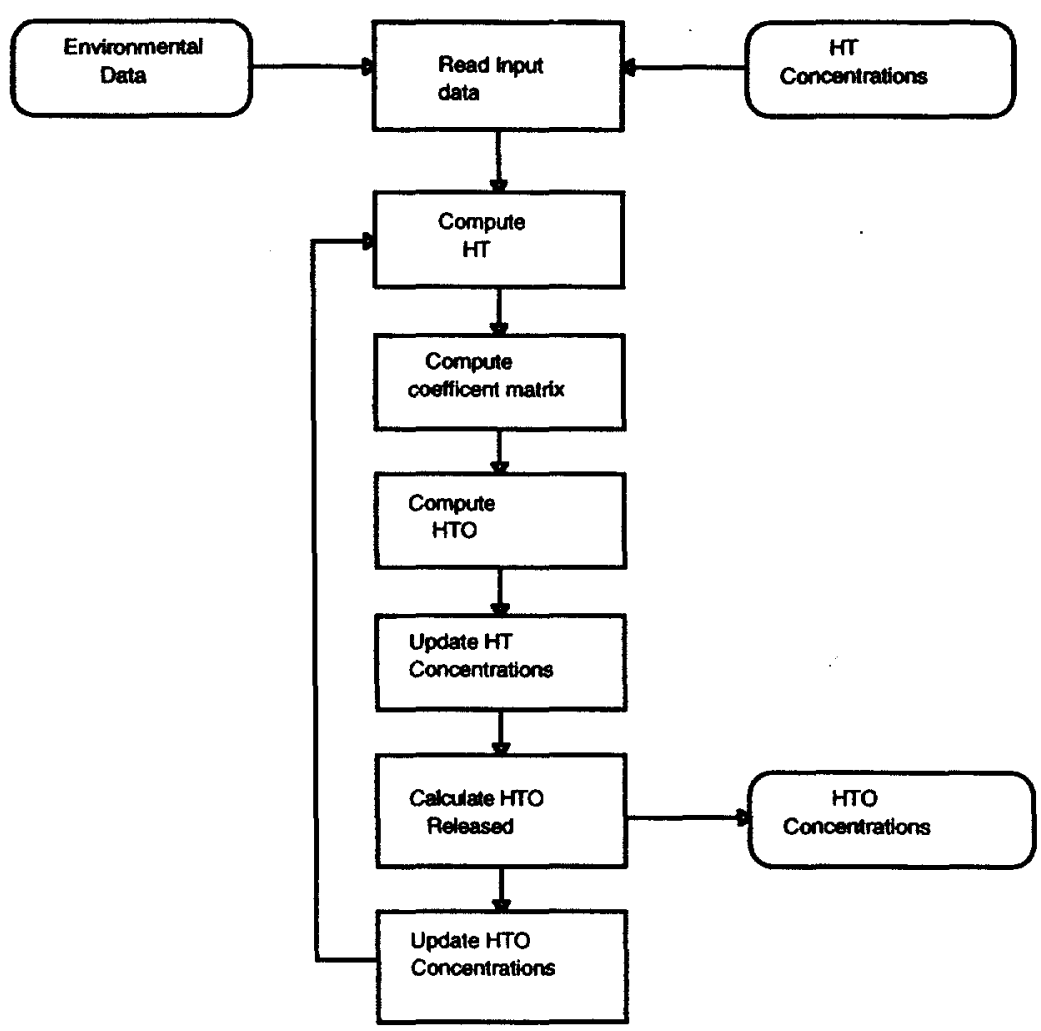

figure 2.

In figure 2. the coefficient matrix used to perform the LU decomposition is updated at each time step since it is a function of the plant transpiration rate. From equation (38) it should be noted that the tridiagonal matrix is a function of $K_{v}$ which, is a function of the plant transpiration rate which changes each time step. Unlike the original simulation developed by Russel and Ogram, it is necessary in this simulation to track the concentrations of both HT and HTO within the soil layer at each time step..

The simulation allows the user to select between two types of scenarios. The first assumes that the evapotranspiration rates are constant, while the second scenario solves the Penman-Monteith equation. Currently the first senario uses evapotranspiration constants defined by Russell \& Ogram, however the HT deposition velocity is user selectable. In an emergency response scenario this parameter, and the surface concentration would be supplied by ADPIC.

\section{Results}

In the following examples, we assume a normalized HT spill lasting one hour. The environmental parameters selected for this series of tests are given in table 1 . in appendix $A$. The simulation requires the user to select a vegetation and soil type. Once the selection is made, the environmental parameters are determined from the data described in appendix A and B. We simulated a two day period. Figure 3 is the plot of the concentration of HTO for a twenty-four hour time period for various wind speeds. The amount of HTO released is approximately seven orders of magnitude less than the original amount of HT deposited on the soil surface. In addition, there is a strong diurnal effect, which is particularly pronounced when the windspeed is zero. 


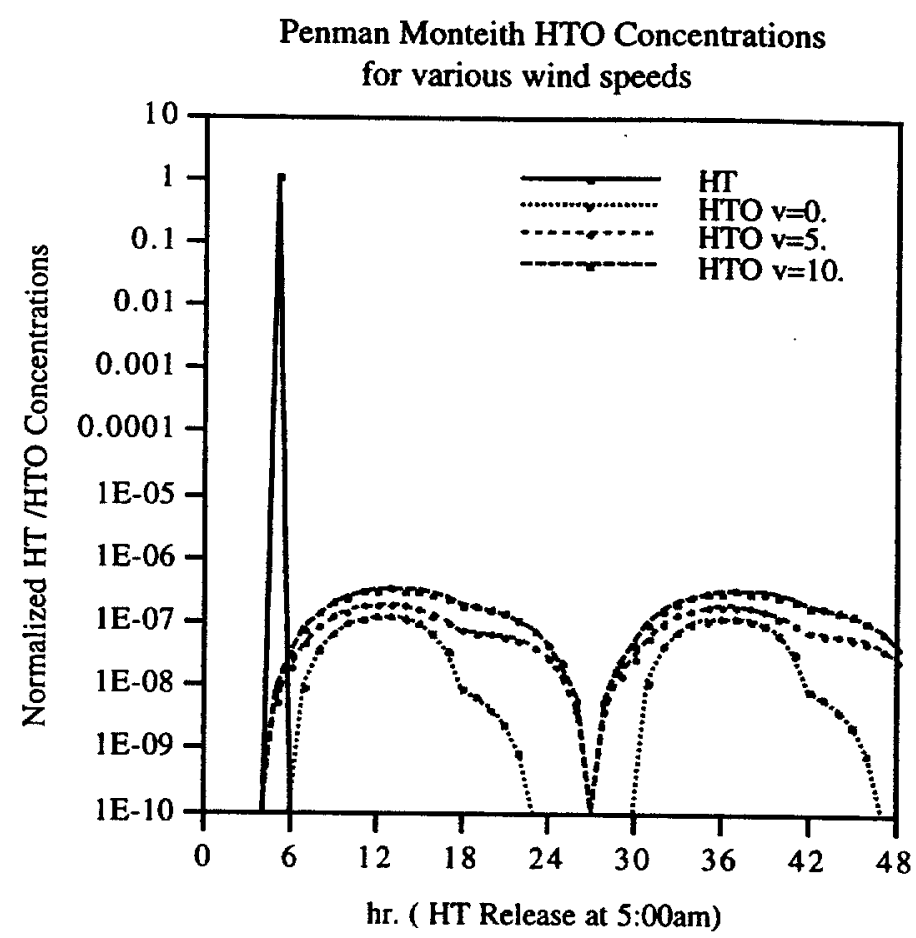

figure 3.

In figure 4. we plot HTO concentrations using typical winter and summer parameters. We set the julian date $=10$, a maximum temperature $=8^{\circ} \mathrm{C}$, a minimum temperature $=-10.0^{\circ} \mathrm{C}$, and a wind speed $=10.0 \mathrm{~m} / \mathrm{sec}$ for typical winter parameters.

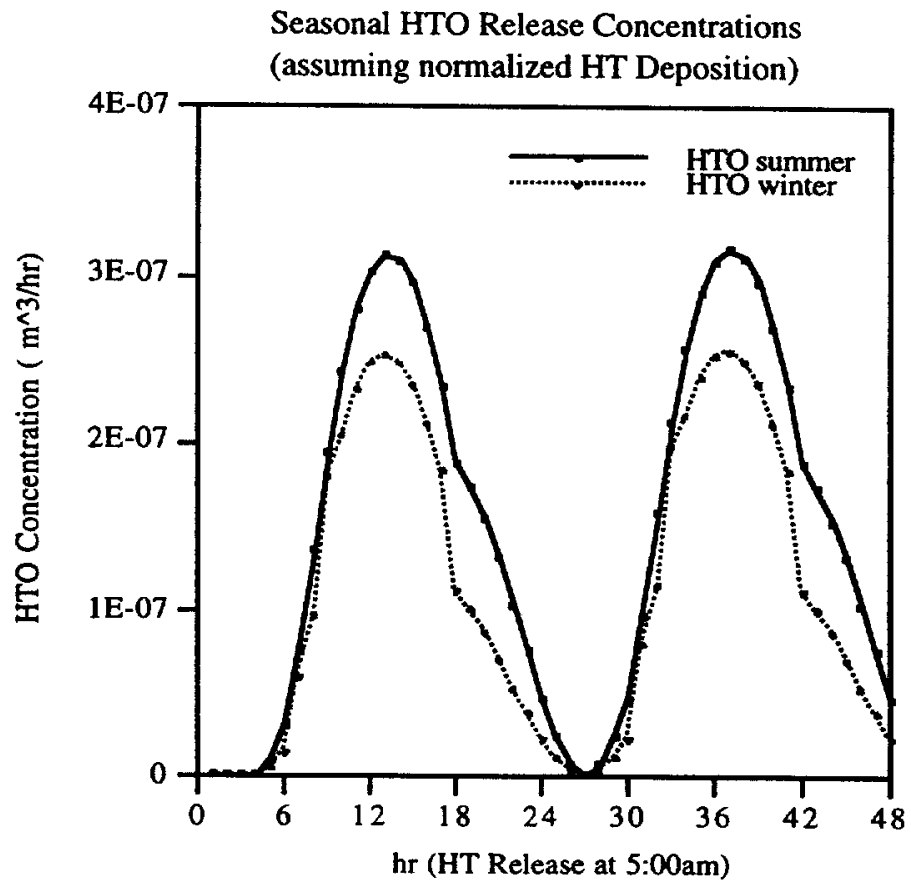

figure 4. 
The summer parameters are a julian date $=190$, a maximum temperature $=30^{\circ} \mathrm{C}$, a minimum temperature of $10.0^{\circ} \mathrm{C}$, and a windspeed $=10.0 \mathrm{~m} / \mathrm{sec}$. The maximum winter plant transpiration rate is $\mathrm{E}=6.540 \times 10^{-5}$ $\mathrm{mm} / \mathrm{hr}$, while the summer plant transpiration rate is $E=1.954 \times 10^{-4} \mathrm{~mm} / \mathrm{hr}$. This appears to be close to the plant transpiration rates predicted by Monteith etal. [14].

In figure 5. we plot plant transpiration rates $\left(\mathrm{m}^{3} / \mathrm{hr}\right)$ for various types of vegetation. The computed values agree with similar calculations made by Kreith and Sellers [23].

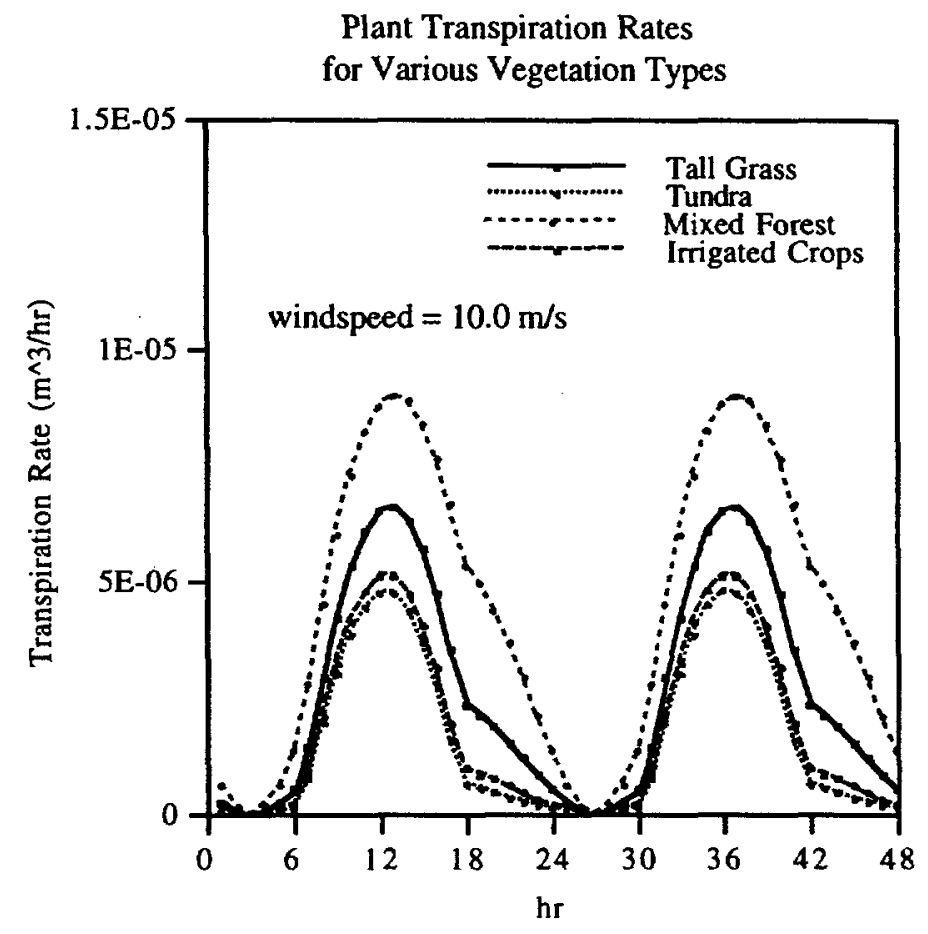

figure 5

In figure 6. we examine the plant transpiration rates at various wind speeds. The Penman-Monteith equations is a function of the apparent psychrometer constant, $\gamma^{*} \cdot \gamma^{*}$ is a function of the total conductance, $\mathrm{K}_{\mathrm{hr}}$ which is the sum of the boundary layer and radiative conductances. The boundary layer conductance is, in turn, a function of the wind speed. The radiative conductance, $K_{r}$, is a function of the temperature difference between the soil surface and the air in the vegetative canopy. One would therefore expect a nonzero plant transpiration contribution even in the absence of sunlight. The first term of the PenmanMonteith equation vanishes when the net isothermal radiation, $R_{\mathrm{nj}}$ vanishes, however the second term which is a function of $\gamma^{*}$ and the slope of the saturation vapor concentration function, $s$, which is in turn, a function of the current air temperature in the canopy. For the no-wind conditions, the evapotranspiration rate drops significantly after the sunset where only $\mathrm{K}_{\mathrm{r}}$ is contributing, and at the opposite extreme of a wind speed of $10 \mathrm{~m} / \mathrm{sec}$ there is plant transpiration occuring long after sunset, though at a reduced rate. When the wind speed is of the order of $1 \mathrm{~m} / \mathrm{sec}$ there are small peaks appearing at hour 24,and 30 . At these times there is a stability transition and the sensible heat of the boundary layer undergoes a sign change because the soil temperature is now greater than the air temperature in the canopy. This effect is currently undergoing further study. For windspeeds greater than $3 \mathrm{~m} / \mathrm{sec}$ the contours remain smooth for hours 18 through 30 (no peaks). (Note - in figure 6, we assumed a julian date of 120). 


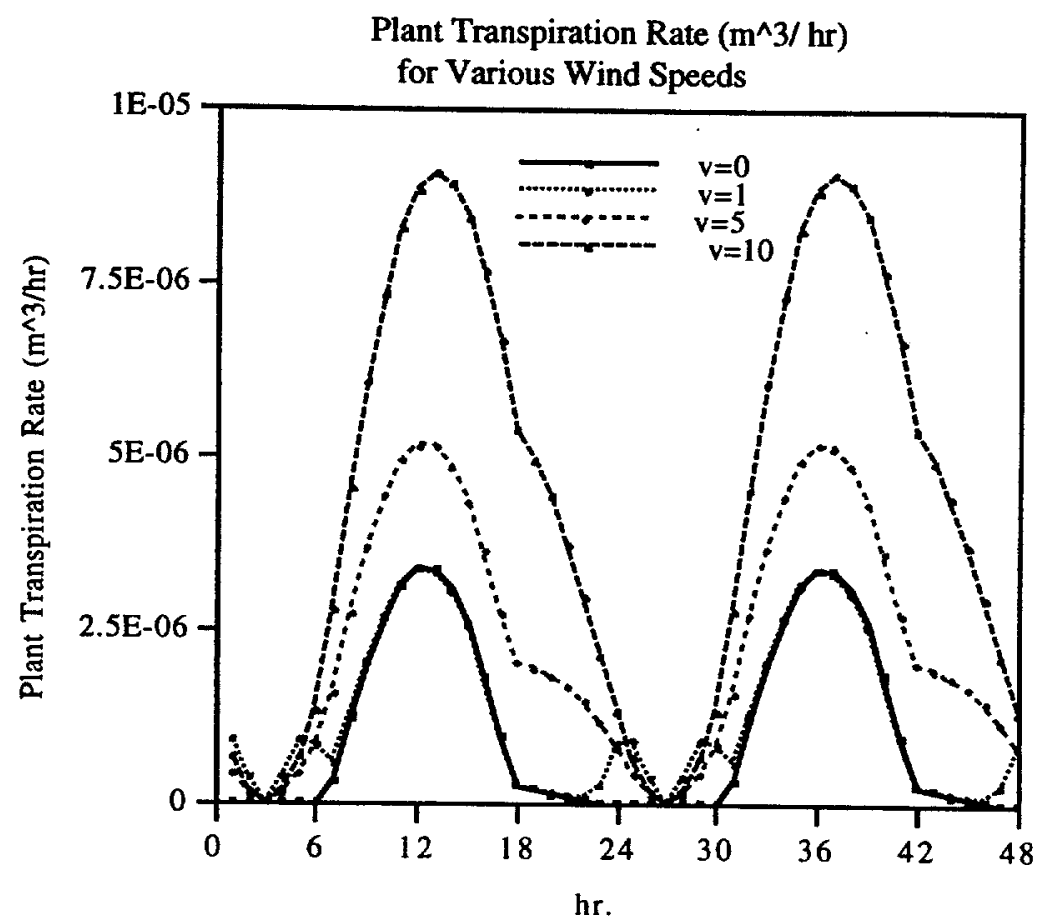

figure 6.

In figure 7. we examine HTO concentrations using constant surface evaporation and plant transpiration rates as suggested by Russell \& Ogram [17].

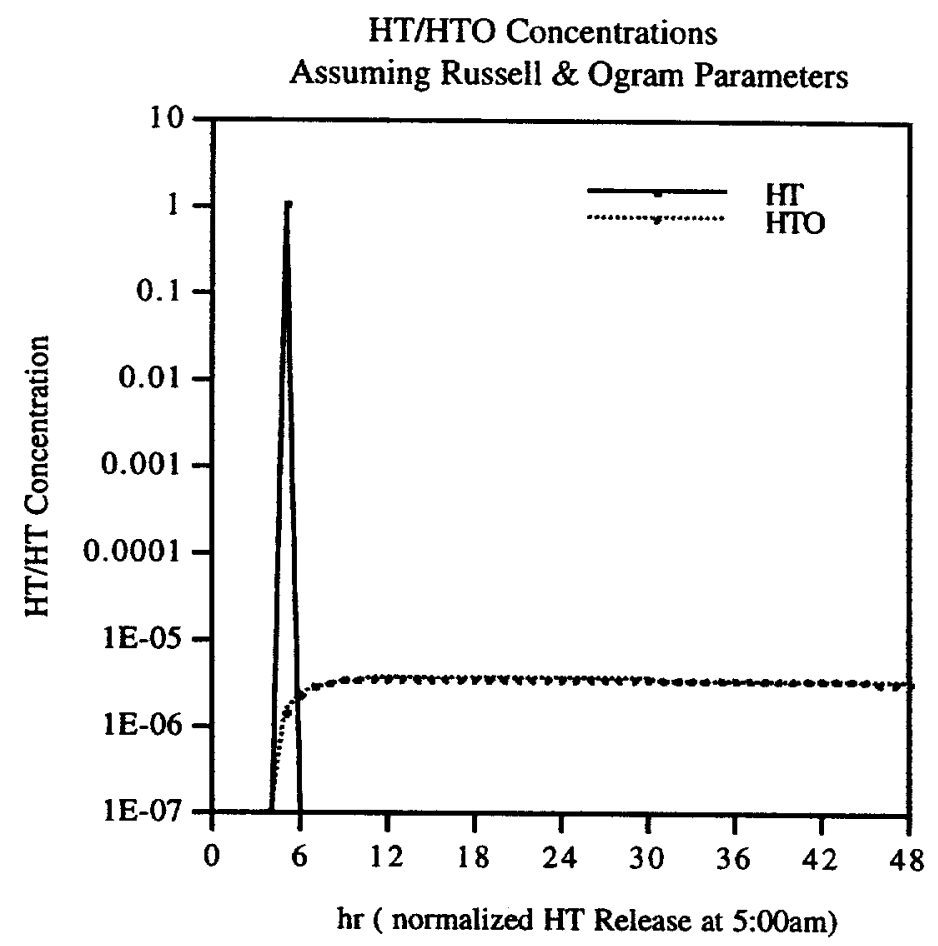

figure 7. 
Russell \& Ogram used a formulation that was originally developed by Garland [2], in which the HTO reemission rate is strongly dependent on the HTO surface exchange velocity and plant transpiration rate, which are measured or estimated constants. In figure 8. we compare the concentration of HTO using the Russell \& Ogram assumptions to the concentration of HTO using to evapotranspiration rates obtained from the Penman Monteith equation.

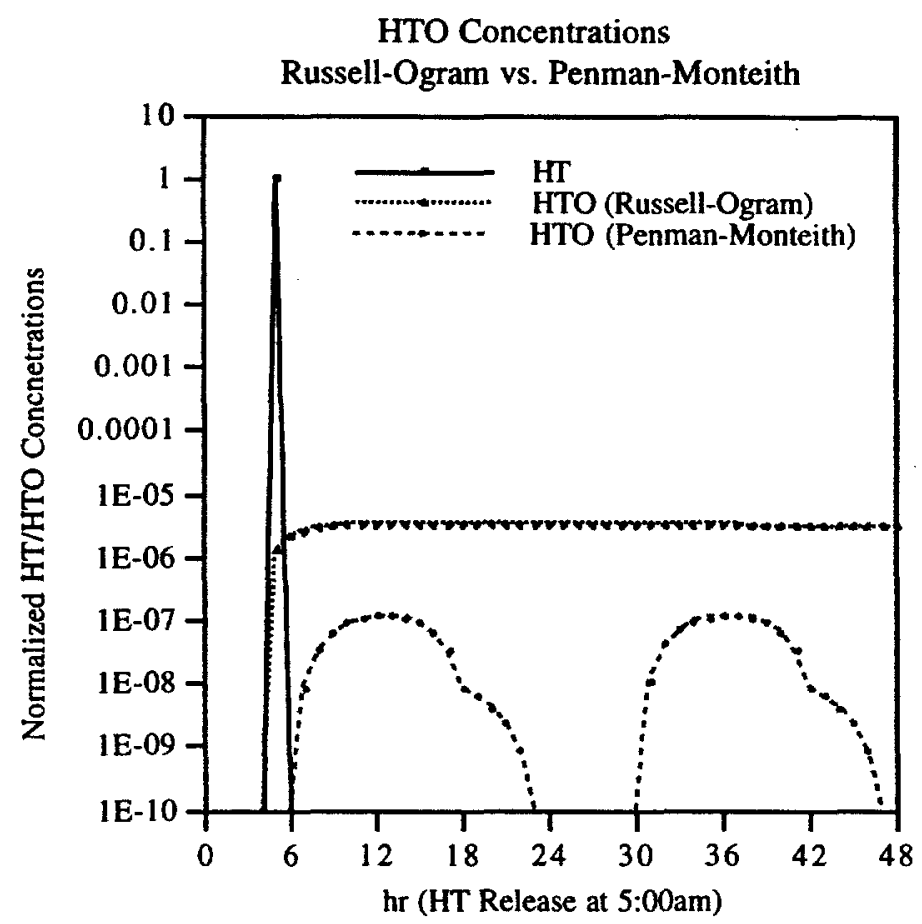

figure 8.

The differences are startling. First, Russell\&Ogram predict HTO concentrations at least a order of magnitude higher than Penman-Monteith. This prediction, if true, should be directly observable from HTO concentration data taken at Sahvannah River [1] and for the Canadian Tritium experiment [17]. If the predictions made by our simulation is true, then the seasonal variables become important and their dynamics must be taken into account. In particular, soil drying, and subsurface water flow must be modeled in more comprehensive manner. In section 4 of this report, the rate of HT transport and conversion is intimately tied to the dynamics of the the soil layer, however the soil layer is severely limited by the assumption of rapid diffusion throughout the entire soil layer. This assumption severely limits the thickness of the soil layer, to the extent that soil thickness greater than a few tens of centimeters are not modeled correctly. In addition, in the current model we have not attempted to model dynamically changing ground water content.

It is well-known [11],[22] that evapotranspiration causes the soil layer to dry, in some cases very rapidly. In the current version of this simulation we have assumed an constant supply of water within the soil layer, hence our simulation may not be realistic for periods greater than a few days to two weeks. In an emergency reponse situation, however, it has been assumed that the environmental parameters remain constant for a maximum of two weeks. Clearly, HTO may reside in the soil layer for significantly longer than two weeks. In order to simulate long term reemission of HTO, a much more comprehensive model is required.

Our simulation indicate that HTO reemission should be considered to be a long-term health hazard that may require monitoring for extremely long periods of time. 


\section{Conclusions}

Two computer programs have been developed which are capable of simulating the reemission of HTO into the atmosphere over a two-week time period. The simulation uses small number of environmental input variables and computes the surface evaporation and plant transpiration by solving the Penman-Monteith equation. By using information extracted from the BATS model, we were able to approximate a number of the salient time dependent features of the boundary layer. The output from the evapotranspiration program is then used to drive the tritium resuspension program. The program is currently in the developmental stage and will require significant additional testing using a number of different enviromental scenarios. In addition, and probably more importantly, the program should be calibrated using actual environmental and concentration data. Data from Savannah River would be invaluable in calibration this effort.

This effort is only a first step in developing a comprehensive computer simulation of the reemission of HTO into the atmosphere. We have not attempted to model the soil dynamics as a function of time. It is well known evapotranspiration from certain soil types is an extremely dynamic process in which the soil can transition from a saturated to a dry state in a matter of days. There have been a number of models developed which attempt to model the soil-atmosphere interface [8], but such models require a significant amount of additional environmental data. There is an encouraging model developed by H.L. Pan and L. Mahrt [22] which requires little additional data.

\section{Acknowledgements}

I thank my colleagues, Dr. Hoyt Walker and Dr. Thomas Sullivan for their technical support and encouragement during the entire project. Their comments and guidance was extremely valuable and greatly appreciated. Work performed under the auspices of the U.S. Department of Energy by the Lawrence Livermore National Laboratory under contract No. W-7405-Eng-48.

\section{References}

[1] Marter,W.L., (1974) "Environmental Effects of Tritium Gas Relase from the Savannah River Plant on May 2,1974"; DuPont Internal Report: DP-1369

[2] Garland, J.A. (1980) Water Air \& Soil Pollution; 13, 317-330

[3] Monteith, (1975) Principles of Environmental Physics, Edward Arnold, London

[4] Idso, S.B., R.D. Jackson, B.A. Kimball, \& F.I. Nakayama (1975) J. App. Meteorol. 14; 109-113

[5] Brutsaert, W. (1975) Water Resour. Res.; 11; 742-744

[6] Bristo, K.L. \& G.S. Campbell (1984) Agric. Forest Meteorol.; 31; 159-166

[7] Campbell, G.S.; (1977) Introduction to Enviornmental Physics; Springer-Verlag; New York

[8] Bussinger, J.A. (1975) "Areodynamics of Vegetative Surfaces"; in Heat and Mass Transfer in the Biosphere; deVries, D.A. \& Afgan N.H. ed.; Wiley, New York 
[9] Monteith,J.L. \& M.H. Unsworth (1991) Principles of Environmental Physics, Edward Arnold, London

[10] Gates, D.M. (1980) Biophysical Ecology; Springer-Verlag; New York

[11] Pielke, R.A. (1984) Mesoscale Meteorological Modelling; Academic Press, New York

[12] Nobel, P.S. (1974) Introduction to Biophysical Plant Physiology; Freeman \& Co. San Franisco.

[13] Penman, H.L. (1948) Proceedings. of the Royal Soc. of London A, 194, 120-145

[14] Monteith, J.L. (1964) "Evaporation \& Enviroment “; 19th Symp. Soc. of Experimental Biol. pg 125

[15] Dickenson, R.E., A.Henderson-Sellers, P.J. Kennedy \& M.F. Wilson; (1986) "BiosphereAtmosphere Transfer Scheme (BATS) for the NCAR Community Climate Model"; NCAR Technical Note: NCAR/TN+275+STR

[16] Xue,Y., Sellers,P.J., Kinter, J.L. \& J, Shukla (1991) Jounal of Climate; 4; 345-363

[17] Russell, S.B. \& G.L. Ogram (1988) Fusion Technology 14; 1193-1198

[18] Bird, R,B, W.E. Stewart, \& E.N. Lightfoot; (1960) Transport Phenomena; John Wiley \& Sons, New York

[19] Strang, G. (1986) Introduction to Applied Mathematics; Welleseley Cambridge Press, Welleseley, Mass.

[20] Press,W.H., B.P. Flannery, S.A.Teukolsky \& W.T. Vetterling (1986) Numerical Recipes; Cambridge Press, New York

[21] Sullivan, T . J. Ellis, C.S. Foster, K.T. Foster, R. Baskett, J.S. Nasstrom, W.W. Schalk (1993) Bulletin of the Am. Meteorological Soc. V42, No 12, 1343-1361

[22] Pan, H.L. \& L Mahrt (1987) Boundary Layer Meteorology; 38; 185-202

[23] Kreith,F \& W.D. Sellera. (1975) "General Principles of Natural Evaporation"; in Heat and Mass Transfer in the Biosphere; deVries, D.A. \& Afgan N.H. ed.; Wiley, New York

[24] Iqbal, M. (1983) An Inroduction toSolar Radiation; Academic Press; Toronto,Canada 


\section{Appendix A}

In this simulation we use the land and soil type descriptions described in the BATS Model [15]. Land surfaces are broken into separate vegetative types and soil types. Table 1. is a list of the required input variables required by the evapotranspiration code. The vegetative types used in the BATS model are described in table 2., and in table 3. the various vegetation land cover values are given for the above eighteen vegetative types are given. In the current version of the tritium reemission simulation we have included all of the vegetative parameters defined in the BATS model however we only use the rouhness length, total soil depth, upper soil depth, Maximum and minimum Leaf area index (LAI) and the minimum stomata resistances. In table 4, we show the soil types defined for this simulation, and in table 5 . we show the values used for the parameters defined for the various soil types.

\section{Table 1: Environmental Parameters}

Meterology Parameters

Julian date:

120.00

Latitude:

38.0000

Maximum temperature:

$30.0^{\circ} \mathrm{C}$

Minimum temperature:

$10.0^{\circ} \mathrm{C}$

Windspeed height:

$13.0 \mathrm{~m}$

Canopy height:

$10.0 \mathrm{~m}$

Windspeed:

$5.0 \mathrm{~m} / \mathrm{sec}$

Precipitation:

Seasonal Soil Temp

Number of Days:

0.00 inches

$15.0^{\circ} \mathrm{C}$

2

Landcover Type : Mixed Woodland

Minimum stomatal resistance

250.0

Maximum leaf area index

Minimum leaf area index

Soil depth

Root depth

Fractional Vegetative Cover

Soil Type : Sandy Clay Loam

Porosity

$0.5100 \mathrm{E}+00$

Suction

$0.2000 \mathrm{E}-01$

Hydraulic Conductivity

$0.4500 \mathrm{E}-02$ 
Table 2: Vegetative/Land Cover Types

1. Crop/Mixed Farming

2. ShortGrass

3. Evergreen needleleaf tree

4. Deciduous needleleaf tree

5. Deciduous broadleaf tree

6. Evergreen broadleaf tree

7. Tall grass

8. Desert

9. Tundra

10. Irrigated Crop

11. Semi-desert

12. Ice Cap/ Glacier

13. Bog or Marsh

14. Inland water

15. Ocean

16. Evergreen shrub

17. Deciduous shrub

18. Mixed Woodland 


\section{Table 3; Vegetation/Land Cover Parameters}

\begin{tabular}{|c|c|c|c|c|c|c|c|c|c|c|c|c|c|c|c|c|c|c|}
\hline Parameter & 1 & 2 & 3 & 4 & 5 & 6 & 7 & 8 & 9 & 10 & 11 & 12 & 13 & 14 & 15 & 16 & 17 & 18 \\
\hline $\begin{array}{l}\text { (a) Max fraction } \\
\text { vegetation cover }\end{array}$ & .85 & 0.8 & 0.8 & 0.8 & 0.8 & 0.9 & 0.8 & 0.0 & 0.6 & 0.8 & 0.1 & 0.0 & 0.8 & 0.0 & 0.0 & 0.8 & 0.8 & 0.8 \\
\hline $\begin{array}{l}\text { (b) Diff between (a) } \\
\text { \& cover @ a temp } \\
\text { of } 269^{\circ} \mathrm{K}\end{array}$ & 0.6 & 0.1 & 0.10 & 0.30 & 0.3 & 0.5 & 0.3 & 0.0 & 0.2 & 0.6 & 0.1 & 0.0 & 0.4 & 0.0 & 0.0 & 0.2 & 0.3 & 0.2 \\
\hline (c) Roughness Length & .06 & .02 & 1.0 & 1.0 & 0.8 & 2.0 & 0.1 & 0.5 & .04 & .06 & 0.1 & .01 & .03 & .0024 & 4.002 & 240.1 & 0.1 & 0.2 \\
\hline $\begin{array}{l}\text { (d) Depth of total } \\
\text { Soil Layer }\end{array}$ & 1.0 & $\mathbf{0}$. & 11.5 & 51.5 & 52.0 & 1.5 & 1.0 & 1.0 & 0.5 & $5 \quad 1.0$ & 1.0 & 1.0 & 1.0 & 1.0 & 1.0 & 1.0 & 1.0 & 2.0 \\
\hline $\begin{array}{l}\text { (e) Depth of upper } \\
\text { Soil layer }\end{array}$ & 0. & 10.1 & 10.1 & 10.1 & 10.1 & 0.1 & 0.1 & 0.0 & $\begin{array}{ll}0 & 0.1\end{array}$ & 10.1 & 10.1 & 0.1 & 0.1 & 0.0 & 0.0 & 0.1 & 0.1 & 0.1 \\
\hline (f) Rooting Ratio & 3 & 8 & 10 & 10 & 10 & 12 & 8 & 9 & 4 & 3 & 8 & 5 & 5 & 5 & 5 & 5 & 5 & 10 \\
\hline $\begin{array}{l}\text { (g) Vegetation Albedo } \\
<0.7 \mu \mathrm{m}\end{array}$ & .10 & .10 & .05 & .05 & .08 & .04 & .08 & .20 & .09 & .08 & .17 & .80 & .06 & .07 & .07 & .05 & .08 & .06 \\
\hline $\begin{array}{l}\text { (h) Vegetation Albedo } \\
>0.7 \mu \mathrm{m}\end{array}$ & .30 & .30 & .23 & .23 & .28 & .20 & .30 & .40 & .26 & .28 & .34 & .60 & .18 & .20 & .20 & .23 & .28 & .24 \\
\hline $\begin{array}{l}\text { (i) Min. Stomatal } \\
\text { Resistance }(\mathrm{s} / \mathrm{m})\end{array}$ & 150 & 250 & 250 & 250 & 250 & 250 & 250 & 250 & 250 & 250 & 250 & 250 & 250 & 250 & 250 & 2502 & 250 & 250 \\
\hline (j) Maximum LAI & 6 & 2 & 6 & 6 & 6 & 6 & 6 & 0 & 6 & 6 & 6 & 6 & 6 & 0 & 0 & 6 & 6 & 6 \\
\hline (k) Minimum LAI & 0.5 & 0. & 55.0 & 1.0 & 1.0 & 5.0 & 0.5 & 0.0 & 0.5 & 0.5 & 0.5 & 0.0 & 0.5 & 0.0 & 0.0 & 5.0 & 1.0 & 3.0 \\
\hline (l) Stem Area Index & 0.5 & 4. & 02.0 & 2.0 & 2.0 & 2.0 & 2.0 & 2.0 & 0.5 & 0.5 & 2.0 & 2.0 & 2.0 & 2.0 & 2.0 & 2.0 & 2.0 & 2.0 \\
\hline $\begin{array}{l}\text { (m) Inverse square } \\
\text { root of leaf } \\
\text { dimension }\left(\mathrm{m}^{1 / 2}\right)\end{array}$ & 10 & 5 & 5 & 5 & 5 & 5 & 5 & 5 & 5 & 5 & 5 & 5 & 5 & 0 & 0 & 5 & 5 & 5 \\
\hline (n) Light Sensitivity & .01 & .01 & .03 & .03 & .03 & .03 & .01 & .01 & .01 & .01 & .01 & .01 & .01 & .01 & .01 & .01 & .01 & .01 \\
\hline
\end{tabular}


Table 4: Soil Types
1. Sand
2. Loamy sand
3. Sandy Loam
4. Silty Loam
5. Peat
6. Loam
7. Sandy clay loam
8. Silty clay loam
9. Clay Loam
10. Sandy clay
11. Silty Clay
12. Clay 
Table 5: Soil Parameters

\begin{tabular}{lllllllllllll} 
Parameter & 1 & 2 & 3 & 4 & 5 & 6 & 7 & 8 & 9 & 10 & 11 & 12 \\
\hline
\end{tabular}

$\begin{array}{lllllllllllll}\text { (a) Porosity } & .33 & .36 & .39 & .42 & .45 & .48 & .51 & .54 & .57 & .60 & .63 & .66\end{array}$

$\begin{array}{lllllllllllll}\text { (b) Max soil Suction } & .03 & .03 & .03 & .20 & .20 & .20 & .20 & .20 & .20 & .20 & .20 & .20\end{array}$

$\begin{array}{lllllllllllllll}\text { (c) Saturated Hydraulic } & .20 & .08 & .032 & .013 .0089 & .0063 & .0045 & .0032 & .0022 & .0016 & .0011 & .0008\end{array}$ Conductivity $(\mathrm{mm} / \mathrm{s})$

$\begin{array}{lllllllllllll}\text { (d) Ratio of thermal } & 1.7 & 1.5 & 1.3 & 1.2 & 1.1 & 1.0 & .95 & .90 & .85 & .80 & .75 & .70\end{array}$ conductivity to that of loam

$\begin{array}{lllllllllllll}\text { (f) Exponent "B" defined } & 3.5 & 4.0 & 4.5 & 5.0 & 5.5 & 6.0 & 6.8 & 7.6 & 8.4 & 9.2 & 10.0 & 10.8\end{array}$ in Clapp \& Hornberger

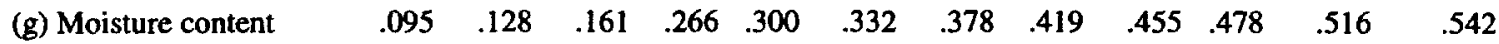
relative to saturation at which transpiration ceases. 


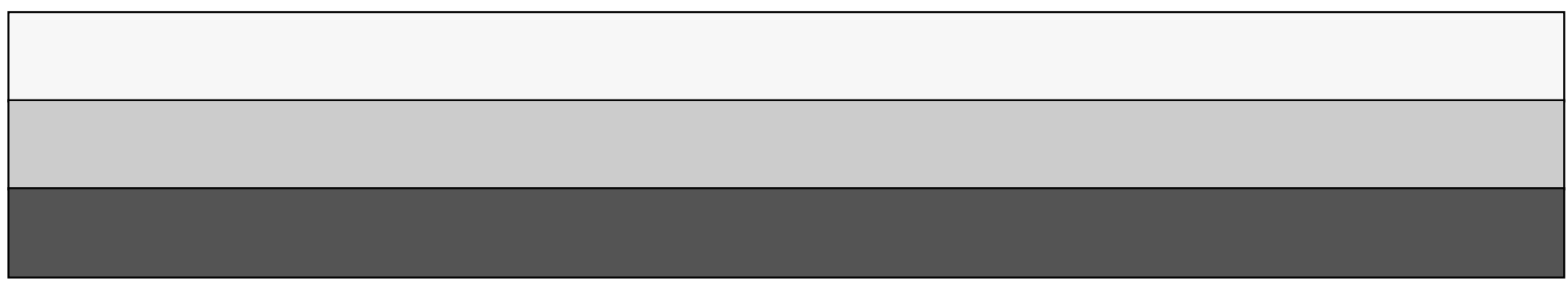

